\title{
Cultural heritage and improvised music in European festivals
}

Tony Whyton and Beth Perry

\section{Introduction: festivals, music and place}

Festivals have an important - if undervalued - position in Europe's cultural ecology, with their dynamic and synergetic relationship to spaces and cultural sites. Within this context, jazz and improvised music festivals provide a distinctive lens through which to explore key issues in heritage research, drawing on music's unique and complex relationship to concepts of high and low culture, tradition, innovation, authenticity and (non)-European identity.

Festivals, music and place: these issues provided the starting point for the 'Cultural Heritage and Improvised Music in European Festivals' (CHIME) project, which ran from 2015 to 2018 under the JPI Heritage Plus programme. CHIME explored how music plays a key role in the sonic refiguring of the urban and rural landscapes, and feeds directly into issues linked to conservation and use, cultural tourism, sustainability, urban regeneration and community engagement. Despite the growing interest in jazz studies as an interdisciplinary field of investigation (Gabbard 1995; Bohlman and Plastino 2016) and in the festivalization of culture (McKay 2015; Cudny 2016), we recognized a clear absence of research that placed jazz festivals within the context of broader heritage studies and the discourses surrounding place-making, the marketization of heritage, urban governance and cultural policy.

CHIME has three main sets of findings. First, we produced a typology of festivals and cultural heritage sites and identified how cultural heritage themes play out in different European festivals today (McKay 2018a, 2018b; Whyton 2018). Second, we identified three themes - improvising, marketizing and 
sounding - which resonated through our three national contexts and case studies, and offered prospects for future research and practice. Finally, we developed a framework for locating jazz festivals, and festivals more broadly, in relation to wider debates about cultural heritage and sustainable development, and set out key proposals around festivals as integrated sites for understanding tangible-intangible entanglements (Perry et al. 2018, 2019).

\section{Chiming together: research approach}

In putting CHIME together, research teams in the UK, Sweden and the Netherlands developed case studies that blended historical and archival research with ethnographic studies and semi-structured interviews to obtain data on specific festivals and the relationships between people, music and festival sites. ${ }^{1}$ In addition, surveys of literature and policy were undertaken in order to place jazz festivals within the broader context of national arts policies and global agendas around sustainable development. Finally, different forms of action research were employed: from the creation of digital tools to be used during festivals to the development of a new annual festival in Birmingham, UK.

As part of their activities, the UK researchers provided an overview of the relationships between jazz festivals and their uses and reuses of cultural heritage. The team undertook a historical survey of European jazz festivals (McKay 2018a), made a study of British jazz festivals and their relationship to the problematic heritage of the transatlantic slave trade (McKay 2018b), and created a typology of cultural heritage sites and European jazz festivals (Whyton 2018). The UK team were concerned with mapping the festival landscape and exploring ways in which the temporal experience and evanescence of festivals could be captured and theorized, and each study sought to place festivals within

The UK team included Professor Tony Whyton (Project Leader), Professor Nicholas Gebhardt (also from Birmingham City University), Professor George McKay (University of East Anglia) and Professor Beth Perry (University of Sheffield). The Dutch team comprised Professor Walter van de Leur, Dr Loes Rusch (University of Amsterdam), Dr Marline Lisette Wilders (University of Groningen) and Beth Aggett (University of Amsterdam). The Swedish team included Professor Helene Brembeck, Dr Niklas Hansen and Dr Olle Stenbäck (University of Gothenburg). We also collaborated with Dr Rike Sitas (University of Cape Town) and Dr Laura Ager (freelance) through funding provided by our Associate Partner, Mistra Urban Futures. 
a heritage context. Whilst this work included theoretical discussions of the cultural value of jazz and its presentation at European festival events (Gebhardt 2016; Whyton 2017), and extensive policy and literature reviews (Webster and McKay 2015), a number of action-based research activities and public engagement events were organized in order to maximize the impact of the project.

In Sweden, research focused on jazz in the urban landscape of Gothenburg. Gothenburg Jazz Festival was disbanded in 2014. However, in 2015, two new festivals emerged that were launched in designated heritage locations; yet each spoke to very different audiences within the city. These were the Classic Jazz Festival and the Gamlestaden Jazz Festival (GMLSTN). Classic Jazz focused on traditional jazz music and tended to appeal to older audiences, whilst GMLSTN was founded as a modern jazz festival that featured younger bands playing experimental improvised music. The Swedish research team, therefore, looked at the city of Gothenburg and its new jazz festivals as consumption sites, and explored the role that heritage plays both in the sustainability of cultural events and the contemporary marketing of jazz. Within this study, the Swedish team examined the role heritage played in the success of each festival, and drew on ethnographic methods to capture and analyse different scenes. Initial surveys of activities included a report on the traditional Classic Jazz Festival, which drew on a series of interviews with a range of actors including festival organizers, musicians and audiences (Liimataine 2016).

The Dutch research team focused on two festival case studies that explored the relationship between festival sites, cultural heritage and different iterations of identity in the Netherlands. The first examined the relationship between improvised music, the bicycle and rural locations, through the lens of the Zomer Jazz Fiets Tour in Groningen. As part of their study, the CHIME team interviewed audiences, organizers and volunteers in order to get a sense of the relationship between music and place, of the feeling of belonging among returning fans, and to develop insights into the tensions at play between the festival experience and the rural heritage location. The second case study included an investigation into tourism and the country's postcolonial history through the North Sea Jazz satellite festival in Curacao (Aggett 2016). In addition to festival case studies, the Dutch team also produced a travelling exhibition of Dutch festivals, working in collaboration with the Dutch Jazz Archive (Rusch 2017).

Our research design also included the identification of Associate Partners within the policy, practice and cultural sectors to support knowledge exchange and dissemination among a wider community of scholars and practitioners. Working with Associate Partner Mistra Urban Futures, we constructed a space 
for dialogue between scholars and practitioners in the Global North and South working on a sister project, 'Cultural Heritage and the Just City'. Through this space, we brought together a transdisciplinary network of scholars and practitioners, including social and natural scientists, arts and humanities scholars and cultural practitioners. The coordination of this comparative learning space at the intersection of these projects brought distinct advantages. It enabled less visible or prestigious 'under-the-radar' festivals to be identified, and it allowed for both the experiential and analytical dimensions of multiple festivals to be surfaced. Through a literature review and common survey, we identified 18 festivals to surface the relationship between tangible and intangible heritage and place. We were particularly interested in thinking about the relationship between the content and place-based context of the festivals as a way of understanding tangible and intangible heritage and sustainable urban development. This also enabled policy recommendations linked to UNESCO Global Challenges and issues of sustainable development (Perry et al. 2018).

\section{Landscapes, themes and concepts: summary of findings}

A diverse blend of traditional qualitative research methods and creative interventions has provided a rich data set for transnational reflection which reveals fresh insights into the landscape of jazz festivals, thematic lenses through which we can interrogate jazz festivals in their specific spatial context and wider questions over the value of festivals in relation to cultural heritage and sustainable urban development.

\section{The landscape of jazz festivals}

Importantly for this collection on heritage planning, jazz feeds into a series of complex questions about the relationship between cultural heritage, sound and place. One area of CHIME's work explored site-specific heritage questions of the contemporary cultural practice of festivals of jazz. It did so by bringing together three areas for discussion and development: questions of slavery heritage and legacy; the location, built environment and (touristic) offer of the historic city; and the contemporary jazz festival, its programme and the senses or silences of (historical) situatedness in the festival package. For example, McKay's work explored the troubling relations between jazz in Britain, historic or heritage locations and venues, and the degree of understanding - or lack of - of the transatlantic slave trade. The studied heritage centres clearly associated with the slave trade that also have significant (jazz) festivals included Bristol, 
Cheltenham, Edinburgh, Glasgow, Hull, Lancaster, Liverpool, London and Manchester (McKay 2018b).

Improvised music can add to the transitory nature of place and encourage unique interventions between people and their surroundings. As Perry et al. $(2018,45)$ state:

Places are not backdrops - but constitutive in themselves ... The site of the festival provides important integrative spaces that are not only geared towards more cohesive human interaction, but foster more engaged relationships between the human and material, where the significance and power of place can be explored through temporary, transient and transitional meeting points.

Jazz festivals, therefore, can be a crucial element in disrupting established ways of thinking about heritage; when jazz enters particular spaces, it can provide a means of engaging with established discourses, reconfiguring histories, encouraging a renewed perspective on a particular location or community and re-engaging with the past. As Whyton (2018) argues, by viewing jazz festivals through the lens of cultural heritage, we can begin to challenge reified presentations of heritage that promote uncomplicated interpretations of nations, people and their associated cultural narratives. Festivals offer meaning to specific groups through acts of remembrance or commemoration. They have the potential to engage with a multitude of voices, and their locations enable people to negotiate a sense of belonging or to (re)consider their place in the world. A typology of festivals and cultural heritage sites demonstrates how concepts of cultural heritage are shifting and are often contested within a festival context. Drawing on interviews with members of the Europe Jazz Network, the following categories emerged to demonstrate how cultural heritage themes play out in different European jazz festivals today:

- Ancient Places/Archaeological Sites

- Historic Towns and Buildings

- UNESCO World Heritage Sites and Cities of Music

- Landscapes, Social Responsibility and the Natural Environment

- Post-industrial Spaces

- Jazz Heritage Festivals

- Heritage and Cultural Tourism

- Voices from the Margins

- Sub-cultural Heritage

- Re-engaging with a National Story/Subverting Dominant Histories

- Heritage as a form of Reconciliation

- Heritage as a Vision of the Future. 
These issues are illustrated further through our case studies in different national contexts.

\section{Improvising, marketizing and sounding jazz}

Through the case studies, we have identified three themes which offer analytical purchase on jazz festivals, cultural heritage and place: Improvising, Marketizing and Sounding jazz.

Improvising draws attention to the potential disruptive function of festivals, which can provide platforms for participation and community engagement, and challenge both the status quo and people's pre-reflexive assumptions around questions of cultural heritage. As part of the CHIME project, Professor Nicholas Gebhardt developed a new 'Grow Your Own Festival' (GYOF) that was aimed at engaging different communities in Birmingham, UK. The event provided an opportunity for different communities to engage in collaborative performance projects and showcases of their cultural backgrounds. A key finding was how the process of creating the festival enabled reflection on questions of identity and what constitutes one's 'own' festival, particularly in the context of debates about DIY cultural activity.

Marketizing draws attention to the cultural and economic value of festivals within heritage settings. Specifically, the Swedish team concluded that why festivals fail or succeed is linked to the ability to measure the impact, value and changing market positions of jazz festivals when tied to heritage sites. Although, in markets such as culture, it is understood that music festivals and heritage sites must maintain an economic balance, the knowledge and experiences exchanged among the public within festival settings are important in themselves rather than reducible merely to economic value and exchange. Social and economic values impact on the behaviour of cultural organizations and individuals and their attitudes to festivals and cultural events. Although festivals' increased status as market(ing) objects has been explored elsewhere, CHIME's work points to the continued need to explore the study of the allocation of culture budgets and the monitoring of culture production via processes of valuation and commensuration.

The Gothenburg case study also reveals the complex relationship between festivals, cultural heritage and space. Gamlestaden Jazz Festival, or GMLSTN JAZZ as it is often written, takes place each spring in the city of Gothenburg and features jazz musicians playing live in multiple venues. It labels itself as a 'modern' jazz festival and the programme brings together famous international touring musicians alongside the city's resident jazz artists. It partners 
with local and regional cultural organizations, but these differ year on year depending on funding. However, the festival maintains a symbolic connection with Kvibergs Kaserner, a military heritage site in Gothenburg and one of its most eye-catching venues (Stenbäck 2017a, 2017b). This building is where the first edition of the festival was held in 2014. Gamlestaden, where the festival originated, is a suburban area in east Gothenburg, where residents come from various countries around the world. There is a mix of cultures here, and another of the ambitions of GMLSTN JAZZ has been to widen the definitions of what jazz is. GMLSTN JAZZ gives greater visibility and coherence to the jazz scene, bringing jazz, as a marginalized form of intangible heritage, to a wider audience. Over time the international orientation has been supplemented by an embeddedness in locality, with family-friendly activities such as learning jazz history.

Sounding draws attention to the acoustics and politics of jazz festivals in their spatial and politico-economic context, with particular attention to cultural and national identities. The ZomerJazzFietsTour (ZJFT), set up in 2000, takes place in the Reitdiep area, a rural area north-west of the city of Groningen, Netherlands. The idea behind the festival was to take advantage of the natural heritage assets of the region and to create alternative settings to experience jazz. This meant showcasing the landscape, churches and barns, as well as promoting more marginalized forms of music. Guests cycle from one church or barn to the next, across 29 locations that host over 30 concerts. The audience is largely Dutch, but increasingly international. There is a strong codetermination between the content and the site: barns and medieval churches have different acoustics, enabling audience members to engage with and appreciate music in distinctive ways dependent on the setting. In this way, the programming is inseparable from the concept of the festival itself. Tangible (natural and built) and intangible (jazz) heritage meet through landscape, place and community. The artists' vision is to counterbalance the dominant jazz festival culture through a match of landscape and location. Yet this is not without its challenges; for instance, in relation to the exponential growth of the festival historically, and the more recent need to limit the numbers of festival-goers in order to protect the natural environment of the region and maintain a balance between conservation and use (Wilders and Rusch 2019).

This case study reflects different approaches towards the reuse of found space either landscape, built environment or both - and was selected specifically for its unusual and contrasting engagement with different types of Dutch heritage. The event offers insights into the significance and values that landscapes, sites and buildings hold for individuals and communities when viewed through the lens of jazz festivals. Additionally, it enables us to understand the meanings 
that cultural heritage holds for people within festival settings and how they perceive, use and interpret it, as well as to explore the contested and conflicting issues around access to cultural heritage when different public spaces are 'festivalized'.

\section{Festivals and sustainable urban development}

Festivals should be recognized for their intrinsic value to populations, rather than simply for their use in place-making strategies. Through an analysis of 18 festivals across the Global North and South, researchers have developed a framework for examining cultural heritage, sustainable development and place through the idea of entanglement (Perry et al. 2018, 2019). Tangible-intangible heritage entanglements are bidirectional, non-linear and co-dependent. While critical heritage scholars increasingly reject a binary, the distinction between 'tangible' and 'intangible' heritage is still used by many: the former refers to physical sites, buildings and artefacts and the latter to practices, representations and expressions that individuals and communities recognize as heritage (Ahmad 2006; Vecco 2010). Festivals are integrative sites where tangible and intangible cultural heritage cohere and collide, with both positive and negative consequences. By integrative sites, Perry et al. (2019) mean festivals where the relationship between context and content is dynamic; where place, meaning and cultural expression combine. The logic of integrative sites further implies plural levels of meaning within festivals themselves, resisting narrow typological differentiations. Festivals provide mechanisms through which plural heritage meanings can be surfaced and valued in the search for more sustainable urban transformations. Festivals can be studied for their subjective and historic meanings of place and culture, as well as their contribution to local economies and tourism strategies.

In a wider context, Perry et al. (2018) argue that festivals offer a way of understanding how international agendas around culture and sustainable development land in different places in the Global South and North. Global agendas around sustainable development have increasingly recognized the importance of place - evident in international frameworks such as the Sustainable Development Goals, New Urban Agenda, Agenda 21 and Agenda 2063. In particular, the urban has become vital for economic growth, social development and ecological sustainability; but cultural heritage has been systematically marginalized from many urban discussions. Despite global assertions that cultural heritage matters, how cultural heritage is activated varies in different contexts. A wide range of assumptions temper how policies are interpreted and actioned on the ground. Festivals can be not only viewpoints on processes of spatial change, but parts of wider processes of transformation. 


\section{Future research and practice directions}

Recognizing the fluidity of heritage is a challenge for policymakers, particularly in a climate where top-down approaches to heritage can perpetuate reified notions of nationhood, identity and belonging. As Laurajane Smith (2006) stresses, heritage research should be discursive; we should not only celebrate and appreciate the value of material things that have been passed on from one generation to the next but also view heritage as a communicative act that encourages people to make meaning for the present day. Heritage can help us understand who we are, as well as who we want to be. Within this context, the project moved from focusing on heritage in terms of historic or meaningful locations to thinking about heritage as a contested subject bound up with concepts of memory, belonging, cultural value and the politics of power, history and ownership.

When thinking about the context and spatial dimensions of heritage, our case studies in Sweden and the Netherlands and review of festivals in the Global South and North emphasize the need to consider different sustainable development outcomes, especially when they relate to environmental issues concerning the natural environment or climate change. The ecologies of festivals and the impact they have on local environments formed an important part of the Dutch and Swedish case studies. The increased presence of people brought by events needs to be carefully managed to minimize any direct detrimental impact on the local natural (and built) heritage from waste, increased footfall and noise disturbances to local wildlife. Organizers should constantly evaluate and re-evaluate different sustainable development outcomes, especially as they pertain to the natural environment and climate change. There is an ever-present risk that the environmental dimension of sustainable development is given less priority than the social and financial dimensions.

Finally, the practice and process of developing festivals are important. The more plural, participatory and collective a process, the greater the potential for unpacking the power of people in place in the festival context. Festivals as critical creative practice should be aiming to trouble, tease or tamper with, rather than perpetuate, the status quo. When festival organizers build in routes to participation in the activities they offer, barriers between spectators and performers can be eroded as they interact and become immersed in the temporal space of the festival. This opens up the possibility of a different kind of cultural politics. Access to resources is a key challenge in this respect; both in terms of enabling marginalized groups to develop their own cultural activities and also in providing opportunities for different communities to gain access to festival 
events, particularly when ticket prices can prove a barrier to participation. Alternative coalitions and partnerships can help to enable marginalized groups to gain access to resources. This is particularly important in the context of the movement to question cultural appropriation and ask whose heritage matters.

\section{Acknowledgements}

In addition to funding from JPI Heritage Plus for the CHIME project, we also acknowledge the financial support of our Associate Partners, Mistra Urban Futures, in co-funding the festivals survey conducted in the Global North and South.

\section{References}

Aggett, B. (2016), 'Building on the power of the past: a political analysis of North Sea Jazz', MA thesis, University of Amsterdam.

Ahmad, Y. (2006), 'The scope and definitions of heritage: from tangible to intangible', International Journal of Heritage Studies 12 (3), 292-300.

Bohlman, P. and G. Plastino (eds) (2016), Jazz Worlds/World Jazz, Chicago IL: University of Chicago Press.

Cudny, W. (2016), Festivalisation of Urban Spaces: Factors, Processes and Effects, Lodz, Poland: Springer International Publishing.

Gabbard, K. (ed.) (1995), Jazz Among the Discourses, Durham NC and London: Duke University Press.

Gebhardt, N. (2016), 'Screening the event: watching Miles Davis' "My Funny Valentine"', in J. Doctor, P. Elsdon and B. Heile (eds), Watching Jazz: Encountering Jazz on Screen, New York: Oxford University Press, pp. 221-38.

Liimataine, M. (2016), 'Town by the riverside - jazz som kulturarv i Göteborg', Gothenburg, Sweden: University of Gothenburg.

McKay, G. (ed.) (2015). The Pop Festival: History, Music, Media, Culture, New York and London: Bloomsbury.

McKay, G. (2018a), 'Festivals', in F. Martinelli (ed.), The History of European Jazz: The Music, Musicians, and Audience in Context, Sheffield, UK: Equinox, pp.407-17.

McKay, G. (2018b), 'The heritage of slavery in British jazz festivals', International Journal of Heritage Studies, doi: 10.1080/13527258.2018.1544165

Perry, B., L. Ager and R. Sitas (2018), 'Festivals as Integrative Sites: Valuing Tangible and Intangible Heritage for Sustainable Development', Sheffield, UK: University of Sheffield.

Perry, B., L. Ager and R. Sitas (2019), 'Cultural heritage entanglements: festivals as integrative sites for sustainable urban development', International Journal of Heritage Studies, doi: 10.1080/13527258.2019.1578987 
Rusch, L. (2017), 'A history of Dutch jazz festivals in thirty-some objects', Amsterdam, The Netherlands: University of Amsterdam, accessed 9 May 2021 at http:// chimeproject.org/wp-content/uploads/2018/03/CHIME-travelling-exhibition-2017 .pdf

Smith, L. (2006), Uses of Heritage, New York: Routledge.

Stenbäck, O. (2017a), 'Where's it at tonight? Discovering an urban jazz festival in Gothenburg, Sweden', Gothenburg, Sweden: University of Gothenburg, accessed 9 May 2021 at https:/gupea.ub.gu.se/bitstream/2077/48858/1/gupea_2077_48858_1 .pdf

Stenbäck, O. (2017b), 'Revisiting Kvibergs kaserner - the home of GMLSTN JAZZ', CHIMEProject.eu blog, accessed 9 May 2021 at http://chimeproject.eu/revisiting -kvibergs-kaserner-the-home-of-gmlstn-jazz/

Vecco, M. (2010) 'A definition of cultural heritage: from the tangible to the intangible', Journal of Cultural Heritage, 11 (3), 321-4.

Webster, E. and G. McKay (2015), 'The impact of (jazz) festivals', Jazz Research Journal, 9 (2), 169-93.

Whyton, T. (2017), 'Moving to higher ground: the changing discourse of European jazz 1960-1980', European Journal of Musicology, 17 (1), 13-22.

Whyton, T. (2018), 'Space is the place: European jazz festivals as cultural heritage sites', International Journal of Heritage Studies, doi: 10.1080/13527258.2018.1517375

Wilders, M.L. and L. Rusch (2019), 'Moving the audience: Dutch landscape experienced through the SummerJazzCycleTour', International Journal of Heritage Studies, doi: $10.1080 / 13527258.2019 .1583271$ 
Tony Whyton and Beth Perry - 9781788974639 Downloaded from PubFactory at 04/26/2023 03:20:05PM via free access 